\title{
Common features associated with spinal-anesthesia-induced hypotension: A retrospective study
}

\author{
STEPHEN M. SWETECH, DO \\ JUSTIN W. CONLON, DO \\ ANTHONY S. MESSANA, DO
}

A retrospective study investigated features common to 85 documented cases of spinal-anesthesia-induced hypotension. Low preoperative systolic blood pressure and anemia were the most predictive features. Physical status was less important, with the exception of emergency surgeries. An association was found between preoperative medication-especially narcotics-and hypotension. Other variables found to have a high frequency among hypotensive patients were known preexisting pathologic conditions, increasing concentrations of anesthetic used at the time of surgery, and increasing levels of anesthesia achieved. The study is weighted toward obstetric/gynecologic cases.

(Key words: Anesthesia, regional anesthesia, hypotension, spinal anesthesia, narcotics, narcotic analgesics)

Spinal-anesthesia-induced hypotension resulting from an anesthetic's sympatholytic action after lumbar subarachnoid spinal anes-

\footnotetext{
From the Departments of Anesthesia and Surgery, Michigan Health Center Hospital, Detroit, Mich. Dr Conlon is chairman, Department of Anesthesia, and Dr Messana is chairman, Department of Surgery. Dr Swetech, a general practitioner, was formerly at the Cooper and Dash Clinic and currently is with the Macomb Hospital Corporation and First Care Medical Center.

Reprint requests to Stephen M. Swetech, DO, 44370 Cadburry Dr, Mt Clemens, MI 48044.
}

thesia is well documented. ${ }^{1-4}$ With comparatively low anesthetic doses, there are negligible direct organ system effects. ${ }^{5}$ Sympathetic blockade to peripheral arterioles, causing vasodilation, profoundly affects spinal-anesthesiainduced hypotension. $1,3,6,7$

Additional interrelated mechanisms eliciting hypotension include the following: loss of venomotor tone, diminishing venous return to the right side of the heart; muscle flaccidity, paralyzing venous segment support; venous return reduction via intra-abdominal pressure alterations and lowered negative intrathoracic pressures, resulting from abdominal muscle relaxation and slowed ventilatory activity; lowered cardiac output; cardiac accelerator fiber inhibition; accentuated vagal tone; attenuated vasoconstrictor response; and decreased stroke volume and peripheral vascular resistance. $1,2,4,5,8-10$

Reportedly, total sympathectomy is attained with spinal anesthesia at or above thoracic levels T-3 or T-4. ${ }^{4,8,11}$ Typically, the level of sympathectomy is two dermatomes above the sensory blockade but may extend as far up as six. 2,8 The more spinal segments involved, the fewer compensatory areas of vasoconstriction, and the more significant the hypotension. 3,11

Some degree of blood pressure decrease occurs almost universally after spinal anesthesia, but significant symptomatic hypotension can have harmful consequences. The purpose of this study was to identify features that could be helpful in predicting high-risk cases. 


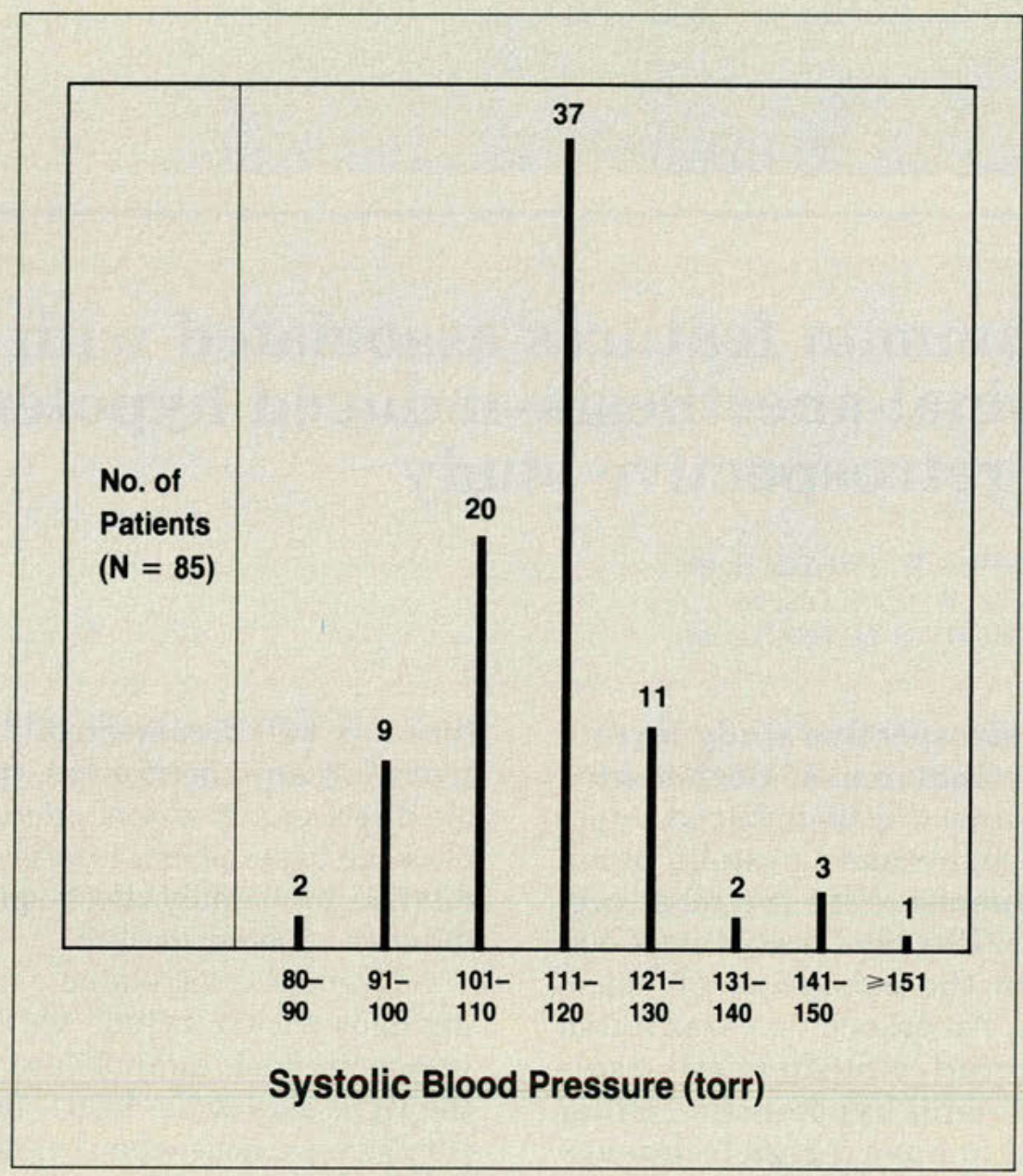

Figure 1. Distribution of preoperative systolic blood pressure values in patients having spinal-anesthesia-induced hypotension.

\section{Materials and methods}

In this retrospective study, we found that 85 (approximately $25 \%$ ) of 366 patients undergoing spinal anesthesia had a significant hypotensive episode. Data from these 85 cases were examined for similarities. The criteria for selection were a drop in systolic blood pressure of 30 torr or more or a systolic pressure decline below 100 torr within 20 minutes of a spinal injection.

The anesthesia reports of all spinal injections performed at Michigan Health Center Hospital from July to December 1986 were examined. The 85 patients in the hypotensive group ranged in age from 17 to 91 years. This group consisted of 17 $(20 \%)$ male and $68(80 \%)$ female patients, including $57(67.1 \%)$ obstetric patients carried to term. No fatalities occurred and patient confidentiality was maintained.

Appropriate standard technique was used, and dosages of all agents used were administered ac-cording to manufacturers' recommendations. A 22- gauge Whitacre needle was used to anesthetize 73 patients; the remaining patients required a 22 gauge regular needle. The anesthetic was introduced into the L3-4 interspace in 83 patients, and into the L4-5 interspace in the other two. Right or left lateral recumbent positioning was required in 17 patients; the others tolerated induction of anesthesia while sitting upright.

Central neural blocking agents injected into the subarachnoid space included $1 \%$ solution of tetracaine hydrochloride (Abbott Spinal Kit No. 4805), $5 \%$ solution of lidocaine hydrochloride (Xylocaine, Kendall Spinal Anesthesia Tray No. 4732), and $0.75 \%$ solution of bupivacaine hydrochloride (Marcaine, Winthrop-Breon) for 57 patients $(67.1 \%), 25$ patients $(29.4 \%)$, and 3 patients $(3.5 \%)$, respectively. Morphine sulfate (Duramorph, Elkins-Sinn) was added to the conduction mixture in 15 cases. An Accutor, Datascope I, or Dinamap automatic oscillotonometric cycling device was used to monitor systemic blood pressure. Glycopyrrolate (Rob- 


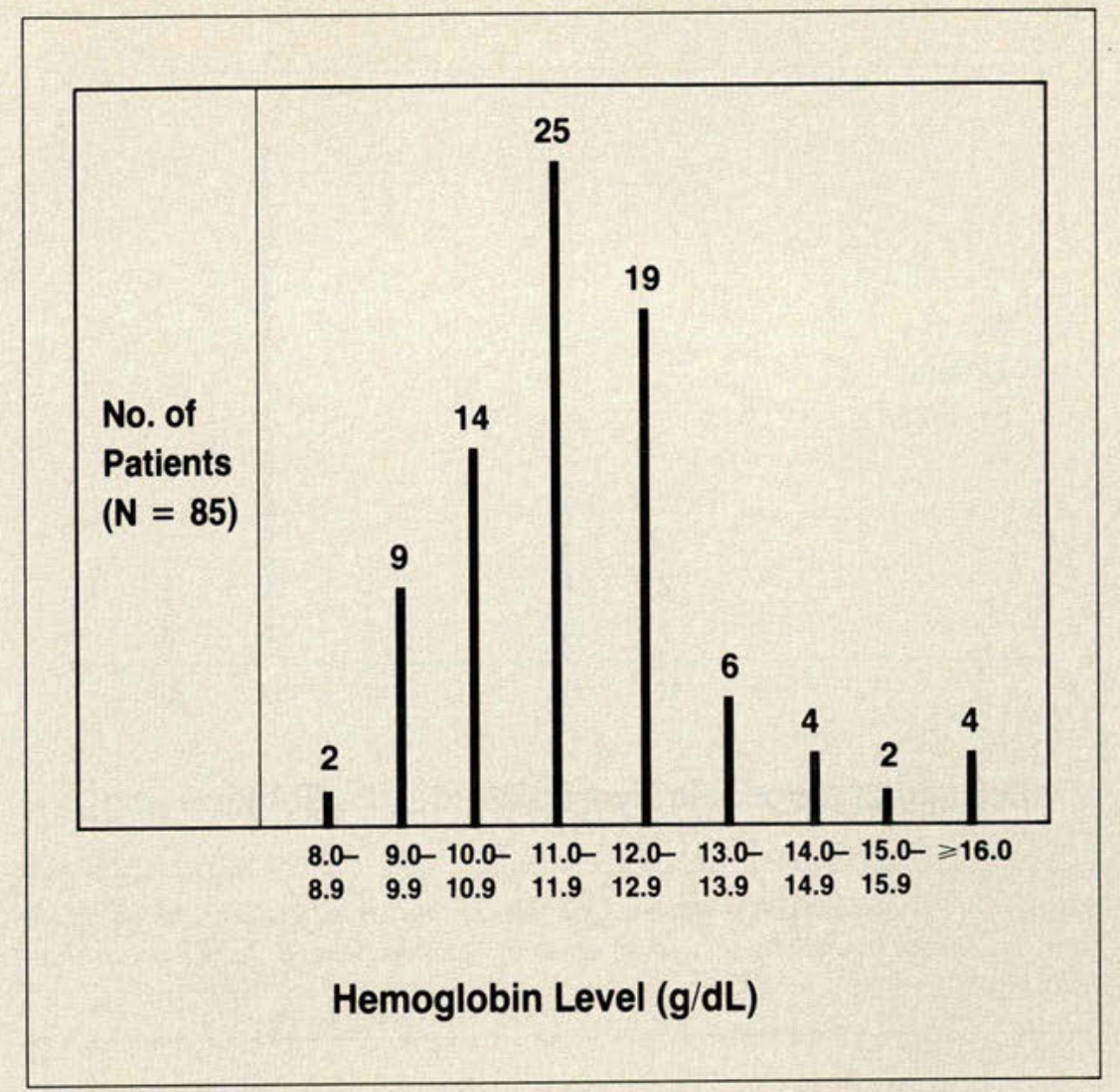

Figure 2. Distribution of hemoglobin values in 53 patients having spinalanesthesia-induced hypotension who were classified as anemic preoperatively. (Anemia was defined as a hemoglobin level of $14 \mathrm{~g} / \mathrm{dL}$ or less in male patients and $12 \mathrm{~g} / \mathrm{dL}$ or less in female patients.)

inul, Robins), atropine sulfate (Inenex), meperidine hydrochloride (Demerol, Winthrop-Breon), fentanyl citrate (Sublimaze, Janssen; and ElkinsSinn), hydroxyzine hydrochloride (Vistaril, Roerig), and midazolam hydrochloride (Versed, Roche) were used preoperatively-individually or in combination-in 18 patients.

Variables examined included preoperative systolic blood pressure, preoperative hemoglobin levels, anesthetic agent and concentration used, spinal level of anesthesia, physical status, preexisting pathologic conditions, preoperative medication, and type of surgery performed. Criteria for patient selection were based on recommendations from references 9 and 11 through 17 (ie, a precipitous reduction of systolic blood pressure $>30$ torr or a decline $>100$ torr within 20 minutes of introduction of the anesthesia).

\section{Results}

It is noteworthy that $80 \%$ of the patients had preoperative systolic blood pressure values of less than or equal to 120 torr (Fig 1). Of the 85 patients, $53(62 \%)$ were classified as anemic preoperatively (Fig 2). Anemia was defined as a hemoglobin level of $14 \mathrm{~g} / \mathrm{dL}$ or less in men and $12 \mathrm{~g} / \mathrm{dL}$ or less in women. Nine men were classified as anemic. Among the 44 women in the study, 37 were gravid. Elevated hemoglobin levels were found in a few patients with preexisting diseases such as chronic obstructive pulmonary disease (COPD).

There was a tendency toward a greater incidence of spinal-anesthesia-induced hypotension with increasing dosages of lidocaine (Fig 3 ). The greatest number of episodes involved patients given dosages of $100 \mathrm{mg}$. Approximately $80 \%$ of the patients having spinalanesthesia-induced hypotension received 10 mg or more of tetracaine (Fig 4); a quarter of 


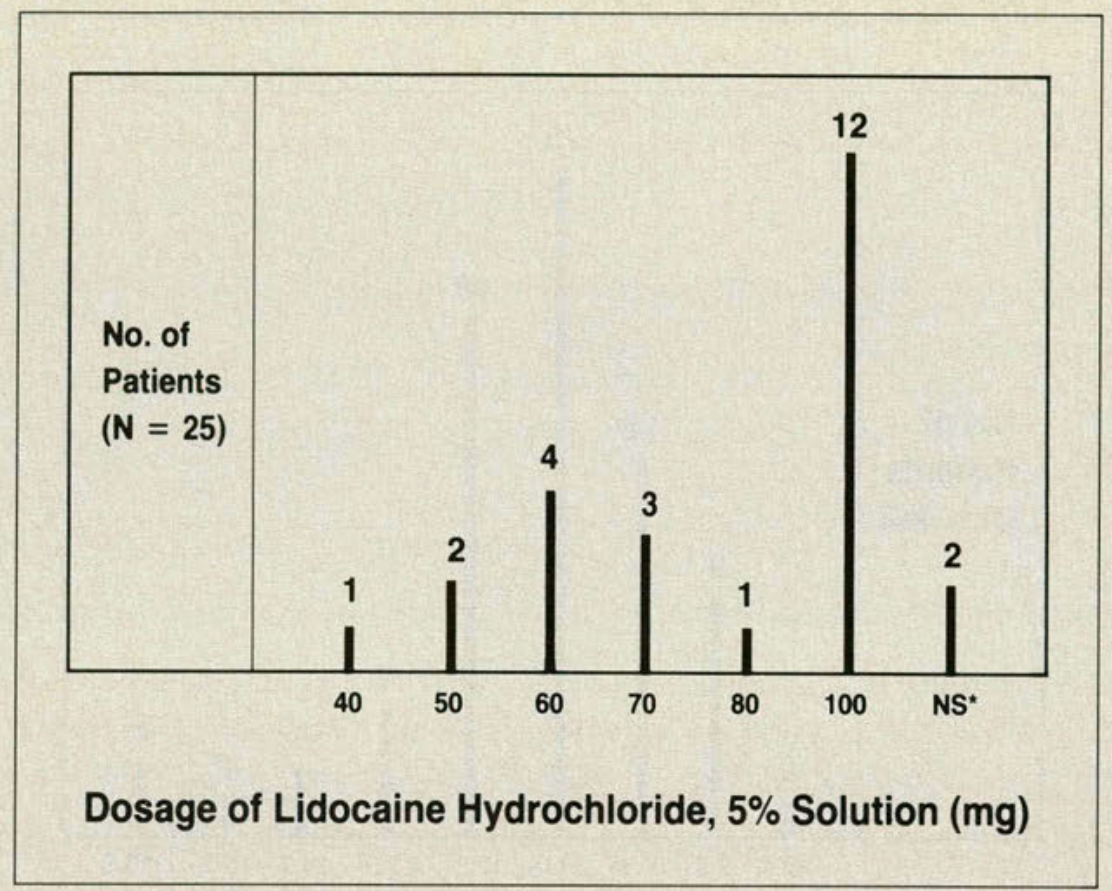

Figure 3. Distribution of patients having spinal-anesthesia-induced hypotension, characterized by administration of various dosages of 5\% solution of lidocaine.

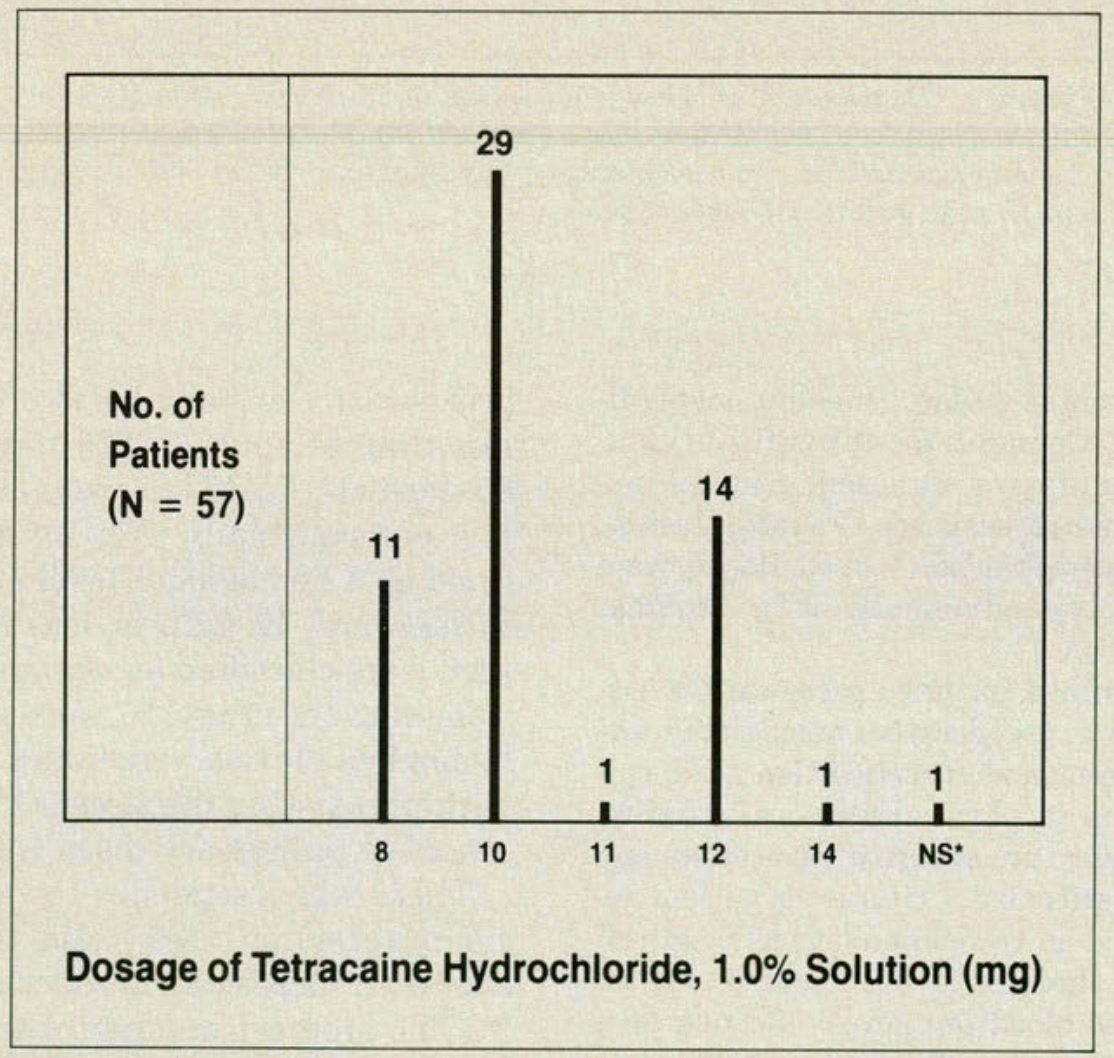

Figure 4. Distribution of patients experiencing spinal-anesthesia-induced hypotension, characterized by administration of various dosages of $1 \%$ solution of tetracaine. ${ }^{*} \mathrm{NS}=$ not specified. 


\section{For Community-Acquired}

\section{Lower Respiratory Tract Infections}

grampositive
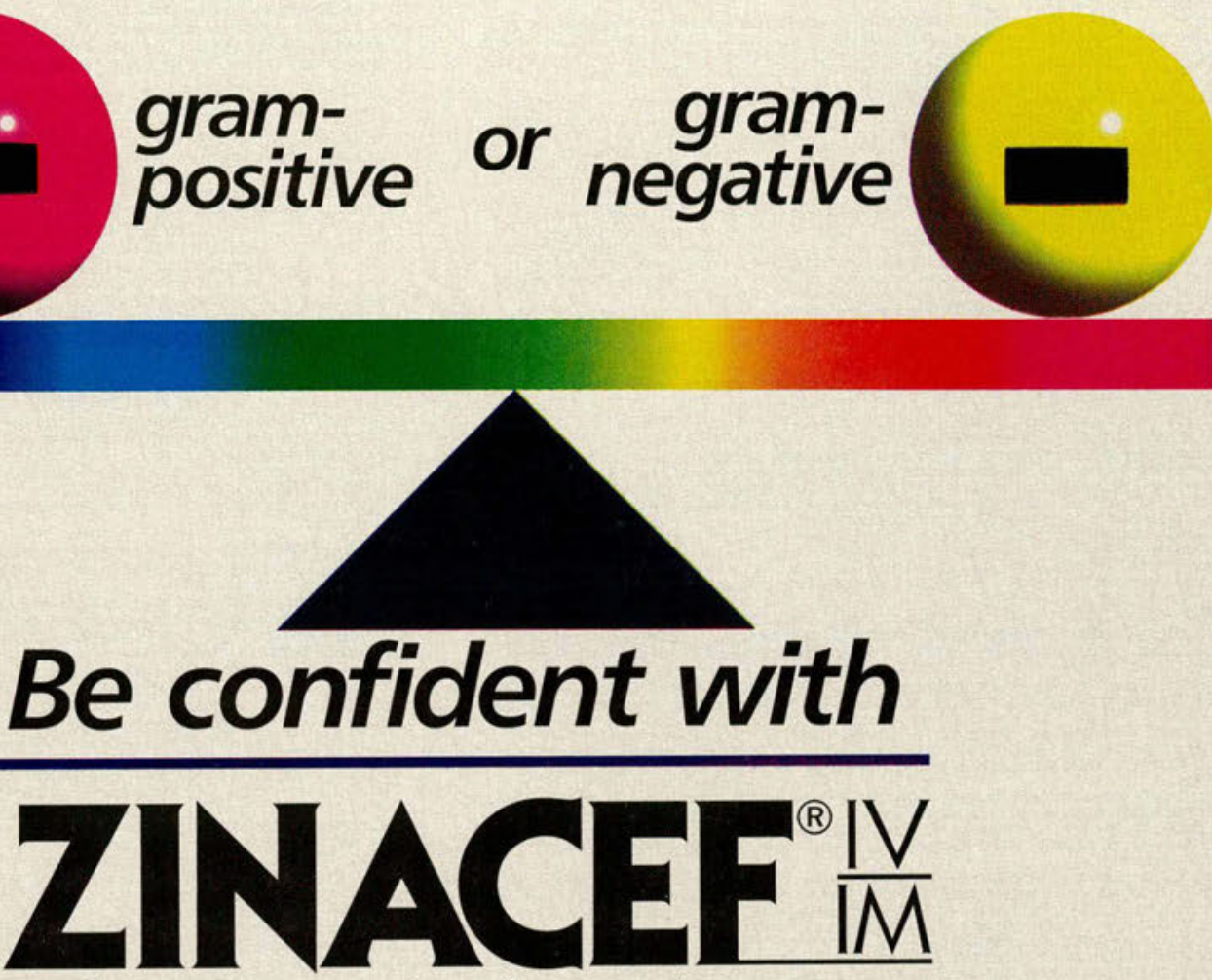

cefuroxime sodium/GLAXO

$750 \mathrm{mg}$ or $1.5 \mathrm{~g} \mathrm{q} 8 \mathrm{~h}$

\section{Balanced Empiric Therapy}

When it's time to convert from IV to oral ...

CEFTIN 'BADLETS (cefuroxime axetil)

For continuity of care

Please consult Brief Summaries of Prescribing Information for ZINACEF and CEFTIN on following page. 


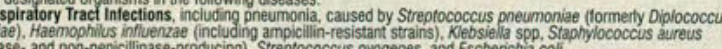

2. Uenicilinase- and non-penicilinase-producing), Streptococcus progenes, and Escherichia colli.

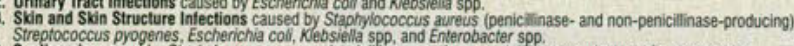

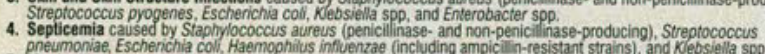

5. Meningitis caused by Streotococcus pneumoniae, Haemoghilus infuenzae (including ampicillin-resistant strains),

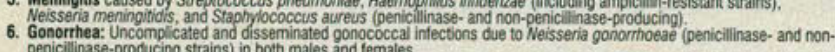

7. Benicililinase-producicing strains) in both males and females. Clinical microbiological studies in skin and skin structure infections treguently reveal the growth of susceptible strains of both aerobic and anaerobic organisms. Znacef has been used successfuly in these mbed infections In which several
organisms have been isolated Appropriate cultures and susceptibility studies should be performed to determine the
susceptbility of the causative organisms to Zinacef Therapy may be started while awating the results of these studies, however, once these results become avaliable, the

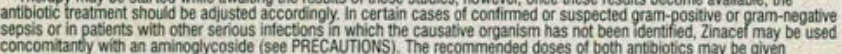
depending on the severity of the intection and the patient's conetion.

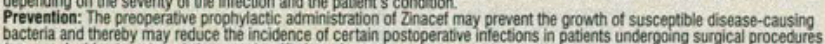
bacteria and thereby may reduce the incidence of certain postoperatve infections in patients undergoing surpical procedures

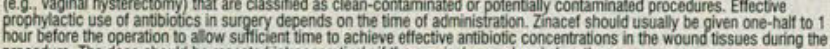
procedure. The dose should be repeated intraoperatively if the surgical procedure is lengothy.
Prophylactic administrabion is usually not required after the surgical procedure ends and should be stopped within 24 hours.

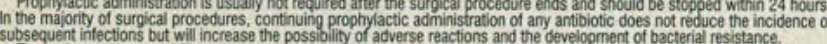

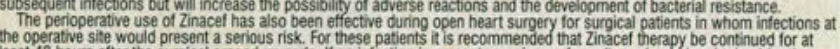
the operative site would present a serious risk. For these patients it is recommended that Zinacef therapy be continued tor at CONIRAINDICATIONS: Znacets is contraindicated in patients with known allergy to the cephalosporin group of WARNINGS: BEFORE THERAPY WITH ZINACEF' IS INSTITUTED, CAREFUL INQUIRY SHOULD BE MADE TO DETERMINE WHETHER THE PATIENT HAS HAD PREVIOUS HYPERSENSTTIITY REACTIONS TO CEPHALOSPORINS, PENICILINS, OR OTHER DRUGS. THIS PRODUCT SHOULD BE GIVEN CAUTIOUSLY TO PENICLLUIN-SENSITIVE PATIENTS. ANTIBIOTICS SHOULD BE ADMINIISTERED WTH CAUTION TO ANY PATIENT WHO HAS DEMONSTRATED SOME FORM OF ALLERGY
PARTICULARLY TO DRUGS. IF AN ALLERGIC REACTION TO ZINACEF OCCURS, DISCONTINUE THE DRUG. SERIOUS ACUTE YPERSENSITIVITY REACTIONS MAY REQUIRE EPINEPHRINE AND OTHER EMERGENCY MEASURES.

Then reported with the use of cephalosporins (and other broad-spectrum antibiotics): Treate, if is wimportant to consider its diagnosis in patients who develop diarrhea in association with antibiotic use.

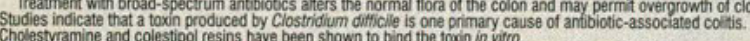
Cholestyramine and colestipol resins have been shown to bind the tocinin in vitro. Mild cases of colitis may respond to drug discontinuation alone. Moderate to severe cases should be managed with fluid, When the colitis is not relieved by drug discontinuation or when it is severe, oral vancomycin is the treatment of choice for
antibiotic-associated pseudomembranous colitis produced by Clostholium difficlie. Other causes of colitis should also be PRECAUTIONS: Although Zinacete rarely produces alterations in kidney function, evaluation of renal status during therapy is recommended, especially in seriously ill patients receiving the maximum doses. Cephalosporins should be given with caution function. The total dalily dose of Znacef should be reduced in patients with transient or persistent renal insufficiency (see DOSAGE
AND ADMINISTRATION), because high and prolonged serum antibiotic concentrations can occur in such individuals from usua As with other antibiotics, prolonged use of Zinacef may result in wergrowth of nonsusceptible organisms. Careful

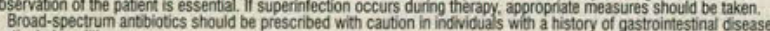
parbcularly colitis. As with other therapeutic regimens used in the treatment of meningitis, mild-to-moderate hearing loss has been reported in hours has also been noted with cefuroxime sodium injection, as well as with other antibiotic theraples; however, the clinical relevance of this is unknown.

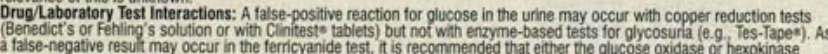
a faise-negative result may occur in the ferricyanide test, it is recommended that either the glucose oxidase
method be esed to determine blood plasma gucose levels in patients receiving Znacet
Cefuroxime does not interfere with the assay of serum and urine creatinine by the alkaline picrate method

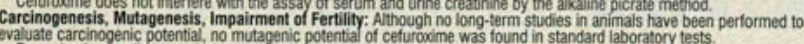
valuate carcinogenic potential, no mutagenic potential of cefuroxime was found in standard laboratory tests. Pregnaduction studies revealed no impalment of tertility in animals.
Pegenic doses up to 60 imes the human dose and have revealed no evidence of imparred fertility or harm to the tetus due to ceturoxime. There are, however, no adequate and well-controled studies in pregnant women. Because animal reproduction
studies are not always predictive of human response, this drug should be used during pregnancy only if clearly needed.
Nursing Mothers: Since cefuroxime is excreted in human milk, caution should be exercised when Zinacet is administered to a Pediatric Use: Safety and effectiveness in children below 3 months of age have not been established. Accumulation of other ADVERSE REACTIONS: Znacefo is generally well tolerated. The most common adverse effects have been local reactions ADVERSE REACTIONS: Znacefo is generally well tolerated. The most common adver
following IV administration. Other adverse reactions have been encountered ony yrarely.

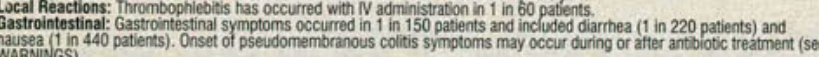
Hypersensitivity Reactions: Hypersensitivity reactions have been reported in fewer than $1 \%$ of the patients treated with Zinacel
and include rash (1 in 125 . Prurtus, urticara, and positive Coombs test each occurred in fewer than 1 in 250 pationts, and.
as with other cephalosporins, rare cases of anaphylaxis, drug fever, erythema multiforme, toxic epidermal necrolysis, and Stevens. Johinson syndrome have occurred.
Blood: A decrease in hemolobion and hematocrit has been observed in 1 in 10 patients and transient eosinophilia in 1 in 14
patients. Less common reactions seen were transient neutropenia flewer than 1 in 100 patients) and leukopenia ( 1 in 750 attients). A similar pattern and incidence were seen with other ceppalosporins used in controlied studilies.
. Hepatic: Translent rise in SGOT and SGPT (1 in 25 patients), akkaline phosphatase (1 in 50 patients), LDH ( 1 in 75 patients),
and bilirubin (1 in 500 patients) levels has been noted.
Kidney: Elevations in serum creatinine and or blood urea nitrogen and a decreased creatinine clearance have been observed.
but their relationship to cefuroxime is unknown.

In addition to the adverse reactions listed above that have been observed in patients treated with cefuroxime, the following Adverse Reactions: Vominting, abdominal bain, colitts, vaginitis including vaginal candididiasis, tow

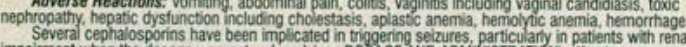

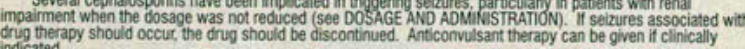

Aftered Laboratory Tests: Prolonged prothrombin time, pancytopenia, agranulocytosis, thrombocytopenia DOSAGE AND ADMINISTRATION: (See complete prescribing intlormation in Zinacete product labeling.). Impaired Renal Function: A reduced dosage must be employed when renal function is impared. Dosape should be HOW SUPPLIED: Zinacete in the dry state should be stored between $15^{\circ}$ and $30^{\circ} \mathrm{C}\left(59^{\circ}\right.$ and $866^{\circ}$ ) and protected from light ZNacef is a dry, white to off-white powder supplied in vials and infusion packs as follows:

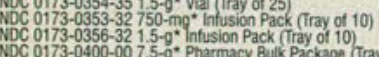

NDC $0173-0400-007.5-0^{*}$. Pharmacy Bulk Packape (Tray of 6)
Zinacef frozen as a prembed solution of ceturoxime sodium should not be stored above $-20{ }^{\circ} \mathrm{C}$. Znacef is supplied frozen in

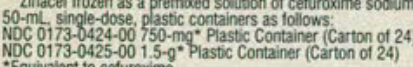

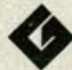

\section{Glaxo Pharmaceuticals}

\section{Allen E Hanburys}

INDICATIONS AND USAGE: Cettin" Tablets are indicated for the treatment of patients with Pharyngitis and Tonsillitis caused by Streptococcus pyogenes (group A beta-hemolytic streptococci). (Penicillin is the usual drug of choice in the treatment and prevention of effective in the eradication of streptococci from the oropharyno. Ceftin Tablets are not indicated for the prophylable.)

susceptible and ampicill Streptococcus pneumoniae, Haemophilus influenzae (ampicillinLind streptococcus pyogenes (group A beta-hemolydic streptococci).

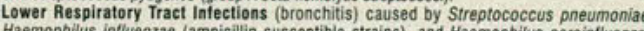
(ampicillin-susceptiole strains)

Skin and Skin Structure Infections caused by Staphylococcus aureus and Streptococcus Bacteriologic studies to determine the causative organism and its susceptiblity to cefuroxime

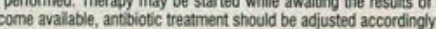
BE MADE TO DETERMENE WHETHER THE PATIENT HAS HAD PREVOUS HYPERSENSITIVTV REACTIONS
TO CEPHALOSPORINS, PENICILLINS, OR OTHER DRUGS. THIS PROOUCT SHOULD BE GIVEN CAUTO ANY PATENT WHO HAS DEMONSTRATED SOME FORM OF AUED BE POMIC STERED WITH CAUTION ALLERGIC REACTION TO CEFTIN TABLETS OCCURS, DISCONTINUE THE DRUG. SERIOUS ACUTE TSERENSITIMITY REACTIONS MAY REOUIRE EPNEPHARE AND OTHER EMERGENCY MEASURES.

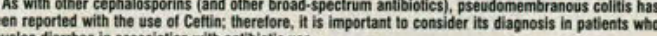
Teap diarmea in association with antibiotic use.

indicate that a toxin produced by Clostriclium difficile is one primary cause of antobiotic-

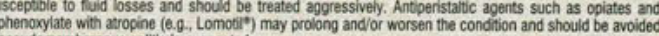
When the colitis is not relieved by drug disconstinuation or when it is severe, metronidazole and oral associated pseudomembranous collits produced by Clostridium difficile. Other causes of colfitis should aliso As with other antbiliotics, prolonged use of Cettin Tablets may result in overgrowth of nonsusceptible
a Brganisms. If superintection occurs during therapy, appropriate measures should be taken.
Broad-spectrum antbiotics should be prescribed with caution for individuals with a history of colitis. Iaformastion for Patients: (Pediatric) Ceftin is only avalable in tablet form. During clinical trials, the table whole may have the tablet crushed and mixed with lood (e.g., applesauce, ice cream). However, it should be noted that the crushed tablet has a strong. persistent, biter taste. Discontinuation of therapy due to the taste Thus, the physician and parent shouid ascertain, preferably while still in the physician's office, that the child

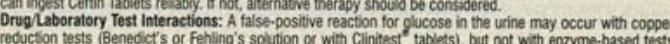

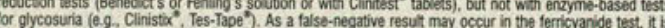
recommended that either the glucose ovidase or hexolinase method be used to determine blood plasma Cefuroxine does not intertere with the assay of serum and urine creatinine by the alkaline picrate method. pertormed to evazuate carcinogenic potential, no mustagenic potential of cofturoxime was found in standard Reoroductive st

Pregnancy: Pregnancy Category B: Reproduction studes have been performed in rats and mice at doses etus due to cefuroxime axetil. There are, however, no adequate and well-controlled studies in pregnan should be used during pregnancy only if clearly needed.

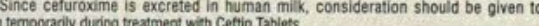
ADVERSE REACTIONS: The adverse reactions to Cettin" Tablets are similar to reactions to other orally

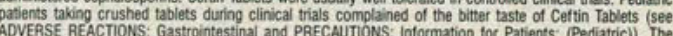
majority of adverse events were mild, reversible in nature, and did not require discontinuabion of the drug 25) patients have received Ceftun Tablets $500 \mathrm{mg}$ twice a day for one to 2.5 monthis with no increase in The following adverse reactions have been reported.

Gastrointestinal: Nausea occurred in $2.4 \%$ of patients. Vomting occurred in $2.0 \%$ of patients. Diarthea occurted in $3.5 \%$ of patients. Loose stools
pseudomembranous colitis (see WARN

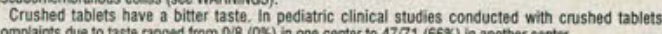
Hypersensitivity: Rash ( $0.6 \%$ of pasents), pruritus $(0.3 \%$ of pasents), and urficaria $(0.2 \%$ of patients) have delayed hypersensitivity to a penicillin and not a cephalosporin, $2.9 \%$ of patients experienced a delayed As with other cepton to cetin Tablets

Central Nervous System: Headache occurred in less anaphylaxis have been reported. han $0.2 \%$ of pasents.

Clinical Laboratory Tests: Transient elevations in AST (SGOT, $2.0 \%$ of patients). ALT (SGPT, 1.6\% of In addition to the adverse reactions listed above that have been observed in patients treated with Ceftin
tablets, the following adverse reactions and altered laboratory tests have been reported for cephalosporinAdverse Reactions: Allergic reactions including colitis, renal dystunction, toxic aplastic anemia, hemolysic anemia, hemorrinage, and pain and/or phlebitis at the injection Several cephalosporins have been implicated in triggering seizures, particularty in with drug therapy should occur, the drug should be discontinued. Anticonvilsant theragy crate Anered Laboratory Tests: Increased prothrombin time, increased BUN, increased eutropenia, thrombocytopenia, leukopenia, elevated bilirubin, pancytopenia, and 


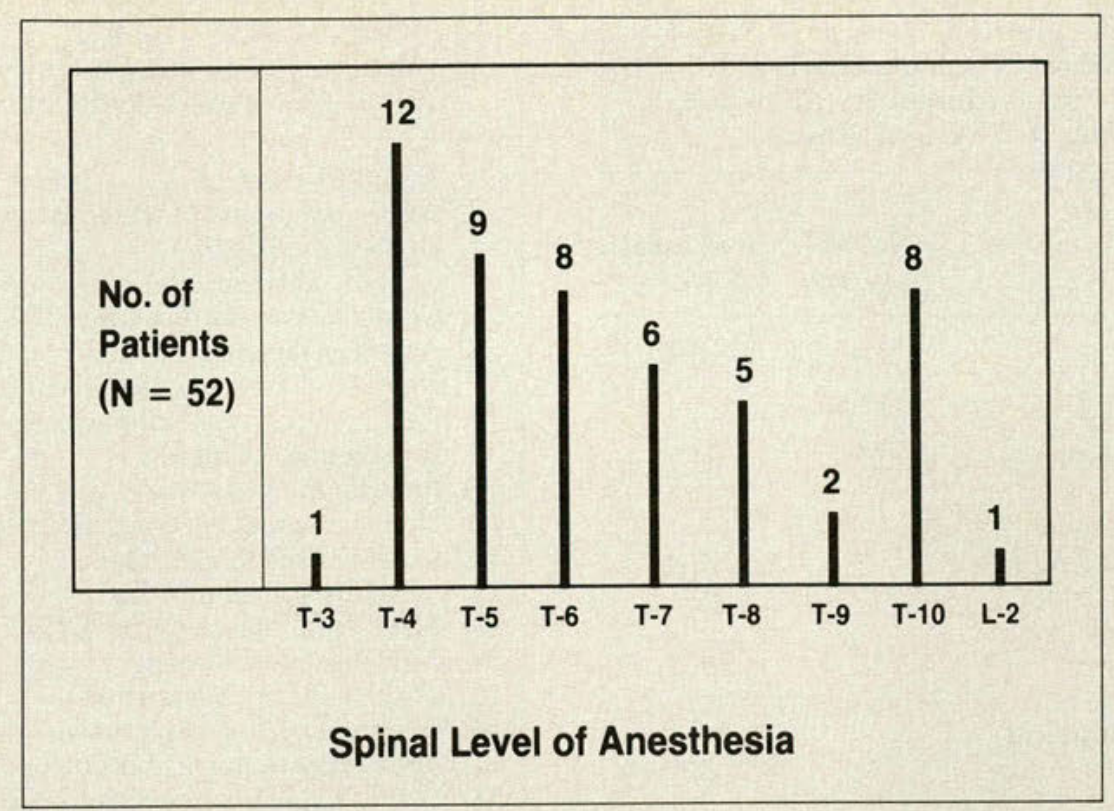

Figure 5. Distribution of patients having spinal-anesthesia-induced hypotension, based on the highest level of anesthesia achieved in the thoracic or lumbar dermatomes. ${ }^{*} N S=$ not specified.

them received $12 \mathrm{mg}$ or more of tetracaine.

Of the 85 patients having hypotension, 52 had their highest level of anesthesia recorded (Fig 5). Thirteen (25\%) of these attained anesthesia to dermatome T- 4 or higher; 30 patients $(58 \%)$ registered anesthesia at T-6 or above. One "high-block" occurred.

The patients all had physical status (PS) determined preoperatively, and expressed as a number from 1 to 5 , according to the severity of the preexisting medical condition. The more severe the condition, the higher the number, according to the following classification: ${ }^{6}$

Class 1 (PS 1): Absence of organic physical mental dysfunction. Examples: elective herniorrhaphy, hysterectomy, or cesarean section in a healthy patient.

Class 2 (PS 2): Mild-to-moderate disturbance, such as controlled diabetes mellitus, hypertension, anemia, or obesity.

Class 3 (PS 3): Severe systemic disturbance or disease, such as debilitating organic heart disease, uncontrolled diabetes mellitus with neurovascular sequelae, severe chronic obstructive pulmonary disease, or a healed myocardial infarct.

Class 2-3 (PS 2-3): Moderate to severe disturbance having mixed features of PS 2 and
PS 3. An obese, diet-controlled diabetic patient experiencing reactive airways from COPD would be a representation of this difficult-toclassify, subjectively assigned group.

Class 4 (PS 4): Severe, life-threatening systemic disorders, such as organic heart disease accompanied by congestive heart failure; persistent symptomatic angina; or advanced pulmonary, hepatic, renal, or endocrine deficiency.

Class 5 (PS 5): Diseases typical of critically ill, moribund patients who have a negligible chance for survival, but who are subjected to surgery in desperation. Examples are patients with a ruptured aneurysm with profound shock, intracerebral bleeding after trauma, or a massive pulmonary embolism.

Emergency operation (E): " $\mathrm{E}$ " is added to any of the previous PS classes when the operation is performed on an emergency basis. Such patients are considered to be in poorer physical condition than their PS classification would otherwise indicate. Examples include an asymptomatic, uncomplicated hernia scheduled for elective herniorrhaphy that incarcerates and subsequently strangulates a portion of bowel, becoming symptomatic; a term pregnancy requiring an emergency cesarean section after 


\begin{tabular}{|c|c|c|}
\hline \multicolumn{3}{|c|}{$\begin{array}{c}\text { Table } 1 \\
\text { Distribution of Patients Having } \\
\text { Spinal-Anesthesia-Induced Hypotension, } \\
\text { According to Physical Status }\end{array}$} \\
\hline $\begin{array}{l}\text { Physical status } \\
\text { numeric } \\
\text { classification* }\end{array}$ & $\begin{array}{l}\text { No. of } \\
\text { patients }\end{array}$ & $\begin{array}{l}\% \text { of total } \\
(N=85)\end{array}$ \\
\hline 1 (Healthy) & 3 & 3.5 \\
\hline $\begin{array}{l}2 \text { (Mild to moderate } \\
\text { systemic disturbance) }\end{array}$ & 55 & 64.7 \\
\hline $\begin{array}{l}\text { 2-3 (Moderate to severe } \\
\text { systemic disturbances) }\end{array}$ & 8 & 9.4 \\
\hline $\begin{array}{l}3 \text { (Severe systemic } \\
\text { disturbance) }\end{array}$ & 18 & 21.2 \\
\hline $\begin{array}{l}4 \text { (Severe life-threatening } \\
\text { disturbance) }\end{array}$ & 1 & 1.2 \\
\hline 5 (Critical/moribund) & 0 & 0 \\
\hline Total & 85 & $\overline{100.0}$ \\
\hline E (emergency procedures) $\dagger$ & $25 \div$ & \\
\hline $\begin{array}{l}\text { "See text for explanation of physical } \\
\text { †The designation "E" is assigned } \\
\text { scheduling of surgery is dictated b } \\
\text { suggests a downgraded condition. } \\
\text { ¥All were in patients who underwen }\end{array}$ & $\begin{array}{l}\text { atus classific: } \\
\text { physical st } \\
\text { an unforeseer } \\
\text { esarean secti }\end{array}$ & $\begin{array}{l}\text { tus when the } \\
\text { emergency; it } \\
\text { n. }\end{array}$ \\
\hline
\end{tabular}

the fetus has been in distress (a large presence in this study). ${ }^{6}$

As shown in Table 1, approximately $70 \%$ of the 85 patients had a physical status rating of PS 1 or 2, which is considered benign. No patient was listed as PS 5, and only one was listed as PS 4.

Among the patients who had spinal-anesthesia-induced hypotension, $18(21 \%)$ had preexisting diseases (Table 2). Three of these 18 patients had carcinoma; 5 had diabetes. A similar number had a vascular disease; 6 had respiratory problems; and 9 had multiple, interdependent pathologic conditions.

Only 18 of the hypotensive patients received preoperative medication (Table 3 ). Narcoticswith meperidine the preferred agent-were administered to 16 patients $(89 \%)$. Fourteen patients $(78 \%)$ received a narcotic/anticholinergic mixture.

Regarding the various types of surgery performed on the hypotensive patients, the high-
Table 2

Conditions Preexisting in 18 Patients Having Spinal-Anesthesia-Induced Hypotension

1. Atrial fibrillation

2. Adenocarcinoma of the prostate gland

3. Diabetes mellitus

4. Chronic obstructive pulmonary disease (COPD)

5. Cerebrovascular disease (CVD)

6. Arteriosclerotic heart disease (ASHD)/ congestive heart failure (CHF)

7. Carcinoma of the endometrium

8. Intravenous drug abuse

9. Pneumonia

10. Upper respiratory tract infection

11. Cerebrovascular accident

12. ASHD/diabetes mellitus

13. ASHD/diabetes mellitus/CHF/COPD

14. ASHD/seizure disorder

15. $\mathrm{COPD} / \mathrm{CVD} /$ hypertension

16. Diabetes mellitus/hypertension

17. Adenocarcinoma of the prostate/hypertension

18. COPD/hypertension/chronic anemia

est proportion were obstetric (Table 4). Urologic and vascular procedures figured prominently among the types of surgery performed.

\section{Discussion}

Certain features were common to the 85 patients who had spinal-anesthesia-induced hypotension. These features are listed in Table 5 in decreasing order of importance.

Low preoperative systolic blood pressure (120 torr or lower) was the most consistent common feature; it was found in $80 \%$ of the patients having hypotension. When systolic pressures of 124 torr and lower are included, the percentage of hypotensive patients increases to $85 \%$. Approximately $13 \%$ of the patients had systolic pressures of 100 torr or less. Elevated pressures of 150 torr or more were discovered in three patients, all of whom had preexisting pathologic conditions; namely, chronic obstructive pulmonary disease, hypertension, and/or diabetes mellitus.

Preoperative anemia, defined as hemoglobin values of less than $14 \mathrm{~g} / \mathrm{dL}$ in men and less than $12 \mathrm{~g} / \mathrm{dL}$ in women, ${ }^{18}$ was also significant in the hypotensive patients. Forty-nine $(58 \%)$ of the patients, irrespective of sex, had hemoglobin levels of less than $12 \mathrm{~g} / \mathrm{dL}$. Among the female patients, whose total number ac- 


\section{Do You Know Where Your Patients' NSAIDs Are?}

500 Fitt
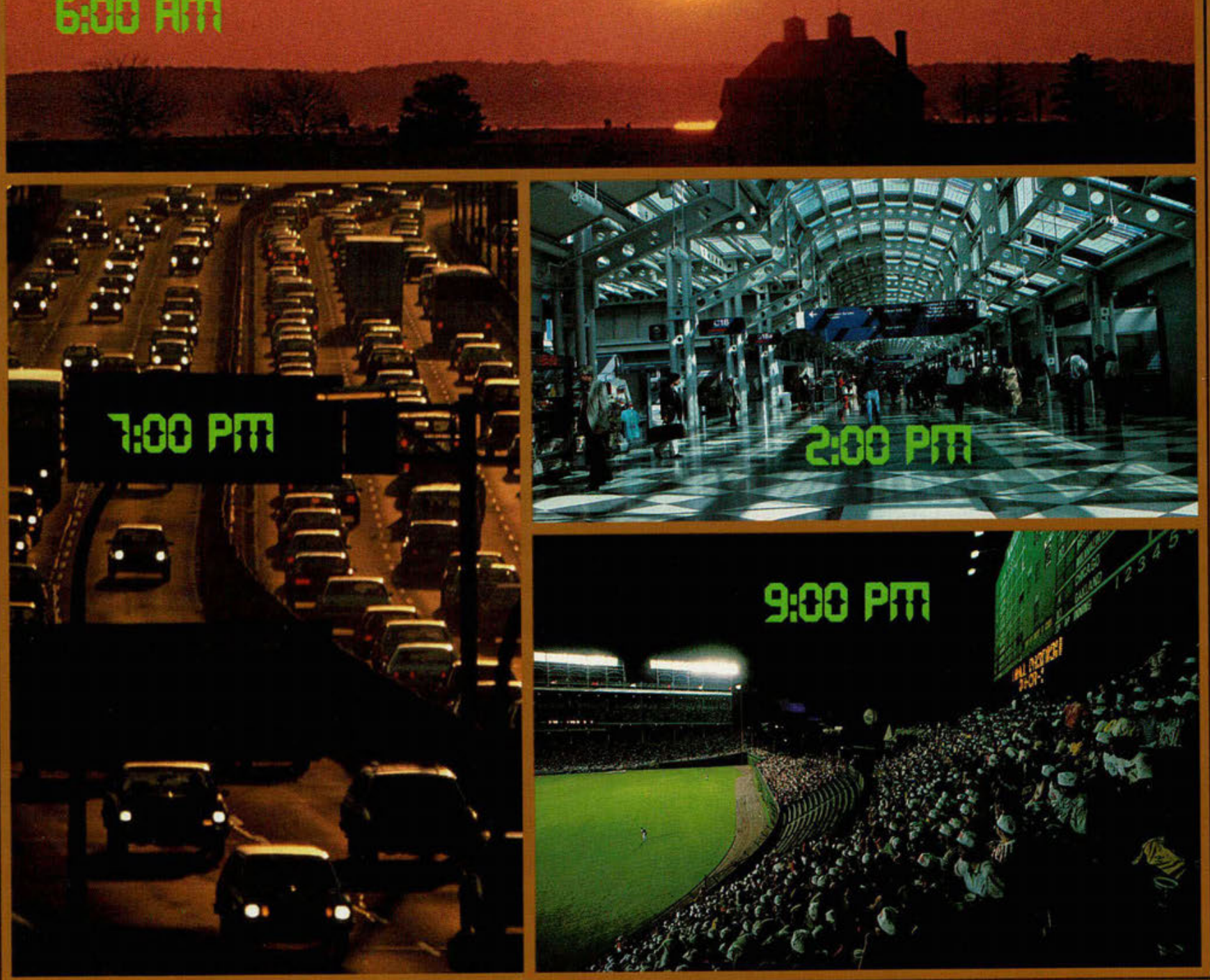

\section{You Know When You Prescribe Once-Daily Feldene \\ (piroxicam)}

Well-Tolerated, Around-the-Clock Arthritis Therapy 


\section{In Osteoarthritis and Rheumatoid Arthritis}

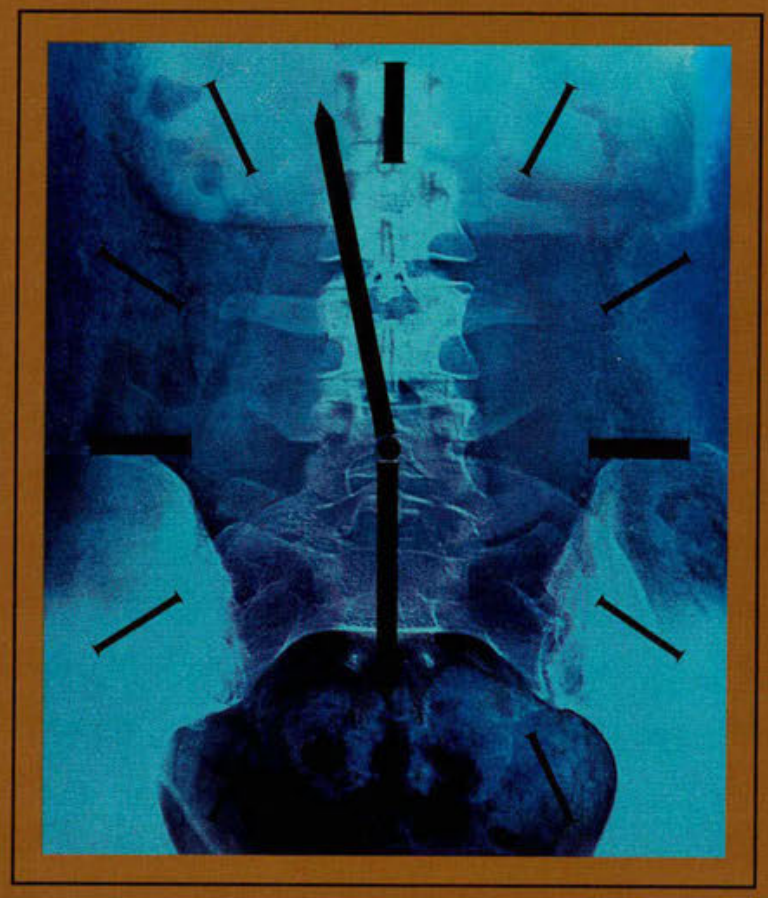

\section{Once-Daily}

\section{Well-Tolerated, Around-the-Clock Arthritis Therapy}

$(P I R O X I C A M))_{\text {capomg }}^{\text {andes }}$

As with other NSAIDs, GI-related side effects may occur in some patients; these include ulceration, bleeding, and perforation.

\section{Briot Summar}

FELDENE (piroricam) Capsules

COMTRandicanows: FEL OENE (piroxicam) should not be used in patients who have previously exhibited hypersensitivit to it, or in individuals with the syndrome compr

Or Other nonsteroidai anti-inflammatory drugs.

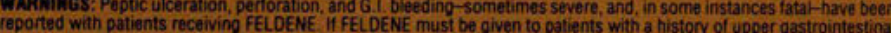
tract disease, the patient should be under close supervision (See ADVEASE REACTIONS). Physicians should remain aler for uiceration and bleeding in patients treated chronically with NSAIDs even in the absence of previous Gil tract symp.

PRECAUnONS: Renal Effects. As with other nonsteroidal anti-inflammatory drugs, long-term administration of piroxicam to animals has resulted in renal Papillary necrosis and other abnomal renal Pathology. In humans, there have been reports o

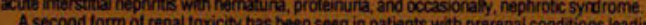

A second form of renal toxicity has been seen in patients with prerenal conditions leading to a reduction in renal blood fiov or biood volume, where the renal prostaglandins have a supportive role in the maintenance of renal perfusion. in thesi overt renal decompensation. Patients at greatest risk of this reaction are those with impaired renal function, heart fallure. iver dystunction, those taking diuretics, and the eiderly.

Because of extensive renal excretion of piroxicam and its biotransformation products fless than $5 \%$ of the daily doe excreted unchanged). lower doses of piroxicam should be anticipated in patients with impaired renal function, and the should be carefully monitored

Aithough other nonsteroidal anti-inflammatory drugs do not have the same direct effect on platelets that aspirin does, all drugs inhibiting prostaglandin biosynthesis do intertere with platelet function to some degre:

Because of reports of adverse eye findings with nonsteroidal anti-inflammatory apents, it is recommended that patients who develop visual complaints during treatiment with FELOENE have ophthaimic evaluation.

As with other nonsteroidal anti-inflammatory drups, borderline elevations of one or more iver lests may occur in up to $15 \%$ of patients A patient with symptoms and/or signs suggesting liver dystunction, or in whom abnormal iver tests hav occurred,
FELDENE.

Severe hepatic reactions, including jaundice and cases of tatal hepatitis, have been reported with FEI DENE. Althouph suct reactions are rare it ahnormal liver tests persist or worsen if clinical sinns and symntoms conseistent with hiver tisease develop, or it systemic manifestations occur (e.g. eosinophilia, rash, etC). FEL DENE should be discontinued (See also ADVEÁSE REACTIONS

Although at the recommended dose of 20 mo/day of FELLENE increased fecal blood loss due to gastrointestinal irritation did not occur, in about $4 \%$ of the patients freated with FELDENE alone or concomitantly with aspinin, reductions in

Peripheral edema has been observed in approximately $2 \%$ of the patients treated with FELDENE. Therefore, FEL DENE should be used with caution in patients with heart failure, hypertension or other conditions predisposing to fluid retenAcon.

A combination of dermatological and/or allerpic signs and symptoms suggestive of serum sickness have occasionality sccurred in conjuncion with the use of FELOENE. These include anthrabias, pruritus, fever, fatigue, and rash including vesiculo bullous reactions and extoliative dermatitis

Therefore, physicians should closely monitor patients for a change in docane reen reported with FEL DENE since marketing. patients on coumarin-type anticoagulants and other highly protein-bound drugs:

Plasma levels of piroxicam are depressed to approximately $80 \%$ of their normal values when FELDENE is administered in conjunction with aspirin ( $3900 \mathrm{mg} / \mathrm{day}$ ). but concomitant administration of antacids has no effect on piroxicam plasema lin ets.

Imels it is ridal anti-inflammatory agents, including FELDENE, have been reported to increase steady state plasma ithium levels. It is recommended that plasma lithium levels be monitored when initiating. adiusting and discontinuino FELDENE: Carcinogenesta, Chronic Animal Toxicity and impaimant of Fentility: Subacule and chronic toxicity studies have been

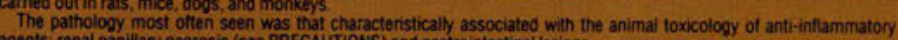
gents renal papillary necrosis (see PRECAUTIONS) and gastrointestinal lesions

classical studies in laboratory animals, piroxicam did not show any teratogenic potentia

Peproductive studies revealed no impairment of fertility in animas

Propancy and Wursing Mothers: Like other drugs which inhibit the synthesis and release of prostaglandins, piroxicar trointestinai tract toxicity was increased in pregnant females in the last trimester of preonancy comnared to animals. Gas temales or females in earlier trimesters of pregnano
FELDENE (piroxicam) is not recommended for use in nursing mothers or in pregnant women because of the animal finc ings and since safety for such use has not been established in humans

Uan in Caidren: Dosage recommendations and indications for use in childten have not been establisher the oatients which in most instances did not intertere with the coerorse of therape efiects, occurring in approximately $20 \%$ o

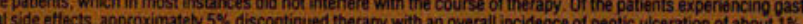
(a)

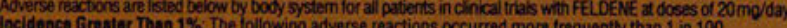

Gastrointestinal: stomatitis. anorexia, epigastric distress:" nausea " constipation abdominal discomtort flatulence, diarthes, abdominal pain, indigestion

Hematological decreases in hemoplobin" and hematocrit" (see PRECAUTIONS), anemia, leucopenia, eosinophills Dermatologic: pruritus, ras.

Central Nervous System: diziness, somnolence, vertipo
Urooenitar: BUN and creatinine elevations (see PAECAUTIONS

Uropenitar BUN and creatinine eleva
Body as a Whole: headache, malaise

Body as a Whole: headaci
Special Senses tinnitus

Cardiovascular/Resoiratorv: edema (see PAECAuTIONS)

- Reactions occurring in $3 \%$ to $9 \%$ of patients treated with FEL OENE. Reactions occurring in $1 \%$ to $3 \%$ of patients are nmarkes.

Incidence Losa Than 1\% (Causal Relationship Probable): The following adverse reactions occurred less frequently than 100. The probability exists that there is a causa relationship between FEL DENE and these reactions.

(iver function ahnom pastroiniestunar bieeding, pertoration and ulceration (see WARININGS), dry mouth

Heristorogical thrombocytopenia, Detechial rash, ecchymosis, bone marrow depression including aplastic anemia, epis Dermatologic sweating, erythema, bruising, desquamation, extoliative dermatitis, enythema multiforme. toxic epiderma crolysis, Slevens -Johnson syndrome, vesiculo bullous reactions, photoallerpic skin reactions

Central Nervous System degression insomnia, nervousnes:

Urogenital hematuria, proteinuria, interstitial nephritis, renal failure, hyperkalemia, olomerulitis, papillary necrosis. Detions)

Body as a Whole pain (colic), fever, flu-like syndrome (see PRECAUTIONS)

Gardiovascular/Respiratory: hypertension, worsening of congestive heart tailure (see PRECAUUTIONS), exacerbation o angina

Hypersensitiving a naphylaxis, bronchospasm, urticaria/angioedema, vasculitis, "serum sickness" (see PRECAUTIONS) Ineidence Lezs Than 1\% (Causalf than 1 in 100 , but a causal relationship between FEL DENE and the reaction could not be determined.

Gastrountestinat: pancreatitis

Dermatologic: onycholysis, loss of hair

Central Nervous System akathisia, hallucinations, mood aherations, dream abnormalities, mentai contusion, paresthesias Urogental Systern: dysuria

Cardiovascular/Respiratory; palpitations, dyspnea

Hypersensitivity positive ANA

Special Senses transient hearing los:

Hematological hemolytic anemia

OVERDOSAGE: In the event treatment for overdosage is required, the long plasma hall-life of piroxicam should be consid ered. The absence of experience with acute overdosage precludes characterization of sequelae and recommendations o specfic antidotal efficacy at this time. It is reasonable to assume that the standard measures ol gastric evacuation and gen? erai supportive therapy would apply In addition to supportive measures, the use of activated charcoal may effectively reduce the absorption and reabsorption of piroxicam. Experiments in dogs have demonstrated that the use of multiple-dose treat ments with activated charcoal could reduce the hali-life of piroxicam elimination from 27 hours (without charcoai) to 11 hours and reduce the systemic bioavailability of piroxicam by as much as $37 \%$ when activated charcoal is given as late as is hours anter administration of piroxicam.

ADMiNISTRATIOW AND DOSAGE: Rheumatoid arthritis, Osteoarthritis: It is recommended that FELOENE therapy be initiat ad and maintained at a singie daily dose of $20 \mathrm{mg}$. If desired, the daily dose may be divided

Mare detailed proftecsional intormation availahis on repuest 
Table 3

Distribution of Patients Having Spinal-Anesthesia-Induced Hypotension, After Administration of Preoperative Medications

\begin{tabular}{|lcc|}
\hline \multicolumn{1}{|c}{ Agents } & $\begin{array}{c}\text { No. of } \\
\text { patients }\end{array}$ & $\begin{array}{c}\text { \% of } \\
\text { total }\end{array}$ \\
\hline $\begin{array}{l}\text { - Meperidine hydrochloride/glycopyrrolate/ } \\
\text { hydroxyzine hydrochloride }\end{array}$ & 4 & 22.2 \\
- Fentanyl citrate*/hyroxyzine hydrochloride & 5 & 27.7 \\
$\begin{array}{l}\text { - Meperidine hydrochloride/hyroxyzine } \\
\text { hydrochloride/atropine sulfate }\end{array}$ & 2 & 11.1 \\
$\begin{array}{l}\text { - Meperidine hydrochloride } \\
\text { - Atropine sulfate/fentanyl citrate† }\end{array}$ & 2 & 11.1 \\
- Meperidine hydrochloride/atropine sulfate & 1 & 11.1 \\
- Atropine sulfate & 2 & 5.6 \\
- Midazolam hydrochloride & 1 & 5.6 \\
$\begin{array}{l}\text { Total } \\
\text { *As Sublimaze (Janssen). } \\
\text { +Fentanyl citrate (Elkins-Sinn). }\end{array}$ & 1 & 5.6 \\
\hline
\end{tabular}

counted for $80 \%$ of the patient population, about two thirds were considered anemic. From a physiologic standpoint, anemia is expected to be associated with hypotension.

Just as some patients had elevated blood pressure, a few (6) patients had elevated hemoglobin levels $(>14.9 \mathrm{~g} / \mathrm{dL})$. These patients also had underlying preexisting pathologic conditions, including COPD, hypertension, leukocytosis, vesical outlet obstruction, or pneumonia.

The results suggest a relation between increased lidocaine concentrations and increased rates of hypotension. This relation was maximally observed at a dosage of $100 \mathrm{mg}$. Only three patients received $15 \mathrm{mg}$ of $0.75 \%$ solution of bupivacaine and consequently cannot be evaluated in terms of dosage. However, the fact that all of the three patients receiving bupivacaine had hypotension may be of importance.

Increasing dosages of tetracaine showed a less linear relationship to the incidences of hypotension compared with lidocaine, but that drug also tended to be associated with higher incidences of hypotension at higher concentrations. The peak incidence of hypotension occurred at $10 \mathrm{mg}$ of $1 \%$ solution of tetracaine.

Although the highest level of spinal anesthesia attained was discovered after the anesthetic was administered, this information may be a predictive factor. Conclusions based on this value are less significant because only $61 \%$ of the patients had the spinal level dermatome reported. Total sympatholysis reportedly occurs at about dermatome T-4 or above. This level is represented by a quarter of those patients whose dermatome levels were recorded.

Considering individual responses to anesthesia and the variable nature of sympatholysis, it can be inferred that dermatome T- 6 or above would approximate total sympathetic inhibition. Such an assumption covers 49 (58\%) of the study's hypotensive patients.

Physical status, a necessary preoperative determination, was evaluated and found to be disappointingly related to spinal-anesthesiainduced hypotension.

No patient had a physical status rating of PS 5-a rating assigned to patients with a neg- 


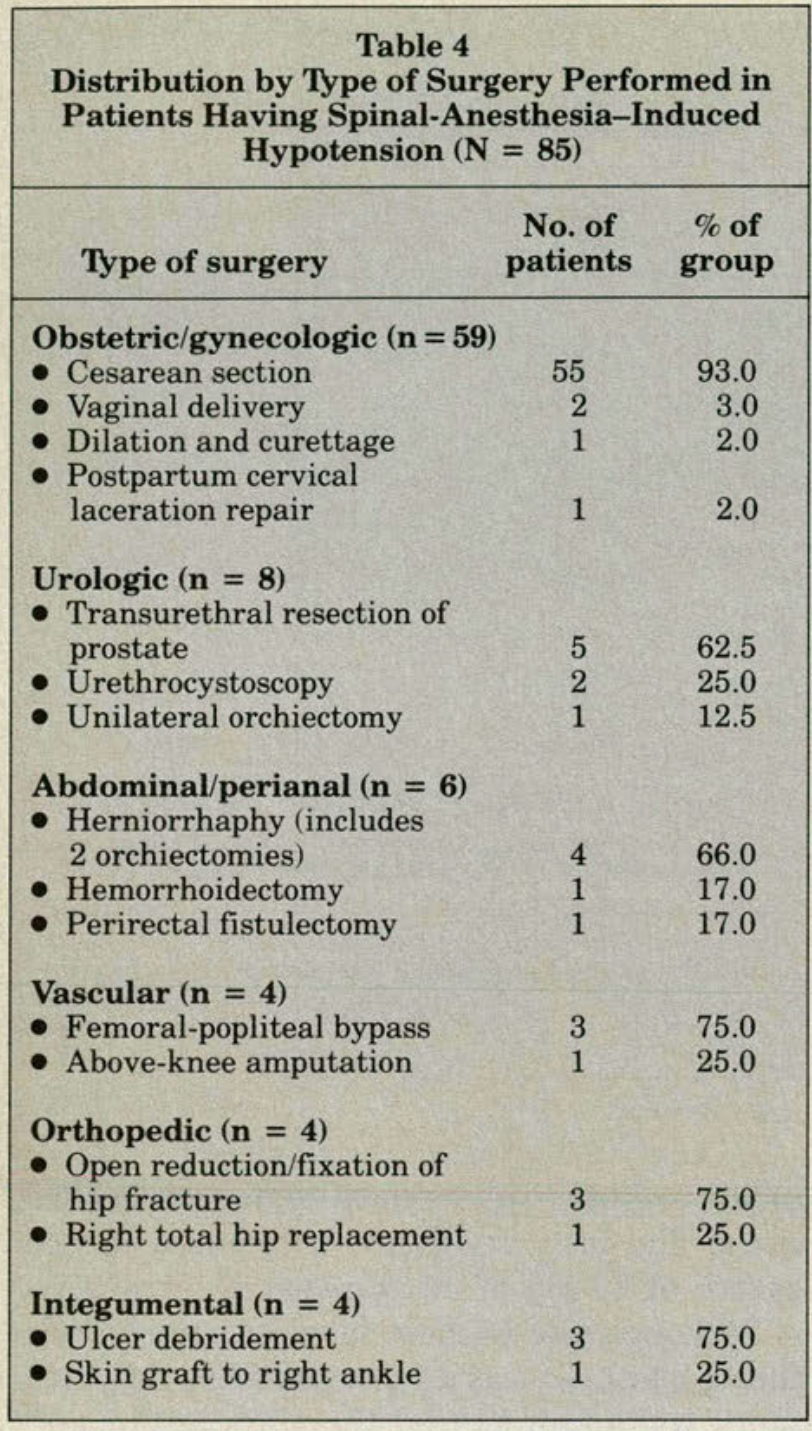

ligible chance of survival. Only one patient was graded PS 4. Most patients (approximately $70 \%$ ) were graded PS 1 or 2 .

This high percentage of benign presentations can be accounted for by the large number of healthy, young obstetric patients, the absence of any substantial number of lifethreatening conditions, and the number of elective surgical procedures. Significant here is the fact that about $30 \%$ of the surgeries were performed on patients graded as PS 2 to 3 through PS 4. Emergency surgery is a separate category in the physical status grading system. In this group of patients, cesarean sections accounted for all 25 emergency surgical procedures.

Documented preexisting conditions were re-

\section{Table 5}

Features Common to Patients Having Spinal-Anesthesia-Induced Hypotension, in Decreasing Order of Importance

- Low preoperative systolic blood pressure $(\leqslant 120$ torr $)$

- Anemia, specifically hemoglobin level $\leqslant 12 \mathrm{~g} / \mathrm{dL}$ irrespective of sex; $\leqslant 14 \mathrm{~g} / \mathrm{dL}$ in male patients

- Increasing dosages of anesthetic

- Spinal dermatomes at T-6 or above

- Physical status class 3 or greater; emergent surgery

- Preexisting conditions

- Narcotic/anticholinergic premedication

- Type of surgery

ported in approximately a fifth of those patients having spinal-anesthesia-induced hypotension. Respiratory complaints led the list, accounting for 6 of the 18 affected patients. The remaining pathologic conditions, listed in decreasing order of prevalence, were diabetes and vascular conditions (including cerebrovascular disease and arteriosclerotic heart disease), 5 (27.8\%); hypertension, 4 ( $22.2 \%)$; carcinoma, 3 (16.7\%); congestive heart failure, 2 $(11.1 \%)$; and chronic anemia, $1(5.6 \%)$. More importantly, half of the patients with documented preoperative conditions had multiple, interdependent diseases.

About a fifth of the patients receiving documented preoperative medication had a hypotensive episode. Narcotic premedication was a common feature shared by 16 patients; a narcotic/anticholinergic mixture was the next most common regimen, administered to $14 \mathrm{pa}$ tients.

Type of surgery was the final variable evaluated. Because Michigan Health Center Hospital is one of the few local hospitals providing obstetric services, cesarean section surgeries are not unusual. This relatively high number of obstetric/gynecologic patients experiencing hypotension was also observed by Kang and associates. ${ }^{19}$

Urologic and abdominal/perirectal surgical (continued on page 1208) 


\section{Managing the Benzodiazepine-Dependent Patient}

Since their introduction almost three decades ago, the benzodiazepines have become one of the most widely prescribed group of drugs in the history of medicine. Despite periodic trends to criticize the broad use of the benzodiazepines, their popularity seems to be well deserved, when one considers the many thousands of references in the worldwide medical literature that clearly reflect the significant benefits realized with these agents. In addition to their more familiar applications in anxiety, insomnia and preoperative sedation, administration of the benzodiazepines extends to certain life-saving uses as well (i.e., control of the muscle spasms of tetanus and other conditions often seen in certain Third World countries).

The potential for abuse and the occurrence of dependence during benzodiazepine therapy has prompted numerous studies and reports. Although physiologic dependence can develop in some patients, available evidence does not appear to support the wide occurrence of abuse in the general population. ${ }^{1}$ However, it is critically important that health care professionals be able to recognize and treat benzodiazepine dependence when it occurs. To assist physicians in this effort, a workshop was held in Basle, Switzerland, in September of 1987. Experts gathered there to evaluate their experiences and establish guidelines for managing benzodiazepine-dependent patients. ${ }^{2}$
These experts agreed that: ${ }^{2}$

- the physician must evaluate a number of behavioral and clinical features and their time course to distinguish benzodiazepinedependent patients from those patients with chronic anxiety who may be suffering from a return of their symptoms.

- some patients should not be withdrawn from therapy even if they show signs of dependence. Careful evaluation of the patient should always precede any attempt at withdrawal.

- while there are many methods available for the safe and effective withdrawal of the benzodiazepine-dependent patient, gradual reductions in dosage in an outpatient setting is preferred in uncomplicated cases.

- continued management of the patient withdrawn successfully is e'Ssential to reduce the patient's risk of relapsing into drug dependency. Of course, the importance of support from the patient's family and friends during and after the withdrawal period cannot be stressed enough.

\section{References}

1. Woods $\mathrm{JH}$, Katz JL, Winger $\mathrm{G}$ : Use and abuse of benzodiazepines: Issues relevant to prescribing. JAMA. 1988;260(23):3476-3479.

2. Marks J: Techniques of benzodiazepine withdrawal in clinical practice: A consensus workshop report. Med Toxicol Adverse Drug Exp. 1988;3(4):324-333.

If you would like more information on the management of benzodiazepine-dependent patients, ask your Roche representative or write to me: Bruce H. Medd, M.D., Associate Vice President and Director, Professional Services, Roche Laboratories, a division of Hoffmann-La Roche Inc., Nutley, New Jersey 07110. 
procedures were the next most common among the hypotensive patients; they were performed in eight (9\%) and six (7\%) of the patients, respectively. Vascular, orthopedic, and superficial surgical procedures accounted for four cases $(5 \%)$. The last three surgical procedure types suggest the presence of renal/cardiovascular pathologic conditions that are related to the feature of preexisting conditions listed previously.

\section{Conclusion}

Certain factors have been found to be associated with spinal-anesthesia-induced hypotension. These factors can help to predict which patients may have significant perioperative hypotension. Anticipation of such occurrences can shorten response time.

Special appreciation is given to Michael M. Patterson, $P h D$, director of research affairs, Ohio University College of Osteopathic Medicine, for providing direction and encouragement in the completion of this article. Special thanks are also accorded to Eldon Nelson, PhD, Medical Education Department, Michigan Health Center, for his assistance and encouragement.

1. Adriani J: Spinal anesthesia; Epidural anesthesia, in Labat's Regional Anesthesia: Techniques and Clinical Applications, ed 4. St Louis, Mo, Warren H Green, Inc, 1985, pp 426-427,459460.

2. Greene NM: Preganglionic sympathetic blockage in man: A study of spinal anesthesia. The Torsten Gordh Lecture, 1980. Acta Anaesthesiol Scand 1981;25:463-469.

3. Spielman FJ, Watson CB: Spinal anesthesia. JAMA 1983;249:734-736.

4. Murphy TM: Spinal, epidural, and caudal anesthesia, in Miller RD (ed): Anesthesia. New York, NY, Churchill Livingstone, 1981, vol 1, pp 655-656,667-669.

5. Pai U: Techniques of nerve blocking, in Raj PP (ed): Hand- book of Regional Anesthesia. New York, NY, Churchill Livingstone, 1985, pp 244-245.

6. Dripps RD, Eckenhoff JE, Vandam LD: Preanesthetic consultation and choice of anesthesia; Spinal anesthesia, in Introduction to Anesthesia: The Principles of Safe Practice, ed 6. Philadelphia, Pa, WB Saunders Co, 1982, pp 17-19,216-225.

7. Lebowitz PW: Common anesthetic problems, in Lebowitz PW (ed): Clinical Anesthesia Procedures of the Massachusetts General Hospital, ed 2. Boston, Mass, Little Brown \& Co, 1982, pp 108-112.

8. Stoelting RK, Miller RD: Spinal, epidural, and caudal blocks; Recovery room, in Basics of Anesthesia, New York, NY, Churchill Livingstone, 1984, pp 173-174,426-427.

9. Snow JC: Complications during anesthesia and the recovery period; Anesthesia in cardiac surgery; Anesthesia and analgesia in obstetrics and gynecology; Anesthesia for emergency surgery, in Manual of Anesthesia, ed 2. Boston, Mass, Little Brown \& Co, 1982, pp 267-268,296,331,401.

10. Moore DC: Single-dose spinal (subarachnoid) anesthesia, in Regional Block: A Handbook for Use in the Clinical Practice of Medicine and Surgery, ed 4. Springfield, Ill, Charles C Thomas Publisher, 1984, pp 353-355.

11. Carron H, Korbon GA, Rowlingson JC: Subarachnoid block; Systemic complications, in Regional Anesthesia: Techniques and Clinical Applications. New York, NY, Grune \& Straton Inc, 1984, pp 45,178.

12. Clark RB: Conduction anesthesia, in Dilts PV (guest ed): Clinical Obstetrics and Gynecology. New York, NY, Harper \& Row Publishers Inc, 1981, vol 24, p 606.

13. Shnider SM: Anesthesia for elective caesarean section, in Shnider SM (ed): Obstetrical Anesthesia: Current Concepts and Practice. Baltimore, Md, Williams \& Wilkins Co, 1970, pp 95,104106.

14. Clark RB, Brunner JA III: Dopamine for the treatment of spinal hypotension during caesarean section. Anesthesiology 1980;53:514-517.

15. Marthru M, Rao TLK, Kartha RK, et al: Intravenous albumin administration for prevention of spinal hypotension during caesarean section. Anesth Analg 1980;59:655-658.

16. Corke BC, Datta S, Ostheimer GW, et al: Spinal anesthesia for caesarean section: The influence of hypotension on neonatal outcome. Anaesthesia 1982;37:658-662.

17. Datta S, Alper MH, Ostheimer GW, et al: Method of ephedrine administration and nausea and hypotension during spinal anesthesia for caesarean section. Anesthesiology 1982;56:68-70.

18. Danforth DN: Other complications and disorders due to pregnancy, in Danforth DN (ed): Obstetrics and Gynecology, ed 4. Philadelphia, Pa, Harper \& Row Publishers Inc, 1982, p 482.

19. Kang YG, Abouleish E, Caritis S: Prophylactic intravenous ephedrine infusion during spinal anesthesia for cesarean section. Anesth Analg 1982;61:839-842. 